\title{
Exploring the characteristics of public reproductive health services in the Islamic Republic of Iran from the perspectives of unmarried women: what needs to be changed?
}

\author{
S. Kohan, ${ }^{1}$ F. Mohammadi, ${ }^{2}$ F. Mostafavi ${ }^{3}$ and A. Gholami ${ }^{4}$
}

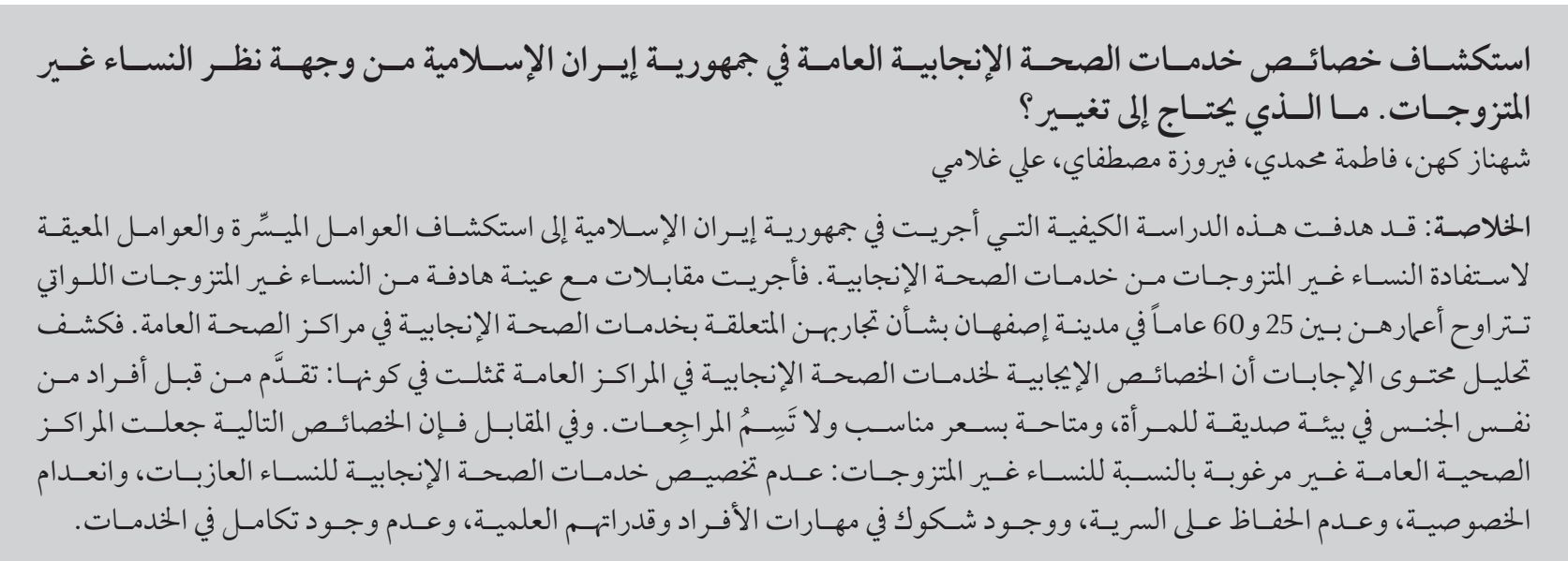

ABSTRACT This qualitative study in the Islamic Republic of Iran aimed to explore facilitators and barriers to the use of reproductive health services by unmarried women. A purposive sample of unmarried women aged 25-60 years in Isfahan city were interviewed about their experiences of reproductive health services in public health centres. Content analysis of responses revealed that the favourable characteristics of reproductive health services in public centres were services that: were delivered by personnel of the same sex in a woman-friendly environment and available at a suitable price, and did not label clients. In contrast, the following characteristics made public health centres undesirable for unmarried women: not addressing single women for reproductive health services; lack of privacy; failure to maintain confidentiality; doubts about skills and scientific ability of personnel; and lack of integration of services.

Étude des caractéristiques des services de santé génésique publics en République islamique d'Iran du point de vue des femmes célibataires. Quels sont les changements à mettre en œuvre?

RÉSUMÉ La présente étude qualitative menée en République islamique d’Iran avait pour objectif de rechercher les éléments favorisant le recours aux services de santé génésique et ceux limitant leur accès aux femmes célibataires. Dans un échantillon choisi à dessein, des femmes célibataires âgées de 25 à 60 ans ont été interrogées dans la ville d'Ispahan sur leur expérience des services de santé génésique dans les centres de santé publique. L'analyse du contenu des réponses a révélé que les caractéristiques favorables des services de santé génésique des centres de santé publique étaient les suivantes : des prestations dispensées par un personnel du même sexe dans un environnement respectueux des femmes et proposés à un prix abordable ; et une absence d'étiquettes attribuées au statut des femmes qui consultent. À l'inverse, les caractéristiques suivantes rendaient les centres de santé publics inattractifs pour des femmes célibataires: I'absence d'orientation des femmes non mariées vers des services de santé génésique ; le manque d'intimité ; le non-respect de la confidentialité ; les compétences et les connaissances scientifiques douteuses du personnel; et le manque d'intégration des services.

${ }^{7}$ Nursing and Midwifery Care Research Centre, Faculty of Nursing and Midwifery; ${ }^{2}$ Student Research Centre, Faculty of Nursing and Midwifery; ${ }^{3}$ Department of Health Education and Promotion; ${ }^{4}$ Department of Islamic Sciences, Isfahan University of Medical Sciences, Isfahan, Islamic Republic of Iran (Correspondence to F.Mohammadi:mohamady_kh@yahoo.com).

Received: 27/03/14; accepted: 08/12/15 


\section{Introduction}

In recent years, the Islamic Republic of Iran has faced a number of demographic and cultural shifts, including increases in the literate female population and in the percentage of female students in university, greater employment of women and greater participation of women in political and social affairs. The effects of demographic transitions and changes in the age composition have led to changes in the pattern of marriage, with an increase in the age of marriage and a higher rate of celibacy (1-3). The average age of women at marriage has gradually increased from 18.4 years in 1966 to 23.2 years in 2002 (4). According to 2012 statistics, women comprised 6.5 million unmarried individuals between the ages of 15 and 44 years (5). The increase in the number of unmarried women in recent years, along with other sociocultural changes, is associated with potentially adverse consequences, such as an increased prevalence of unprotected sexual activity leading to a risk of sexually transmitted infections and unsafe abortions, all of which put an individual's health at risk.

The rise in celibacy and the young population have created new and growing demands in the field of reproductive health (6). Reproductive health is defined as " a state of complete physical, mental and social well-being and not merely the absence of disease or infirmity, in all matters relating to the reproductive system and its functions and processes" (7). The World Health Organization has directed attention to women's needs and the pressures and problems affecting them in different stages of life. This attention is essential to ensuring that reproductive health services attain their goals. This means removing barriers to the use of reproductive health services among different groups of women, especially unmarried women and girls (8).

Studies have shown that in many cultures unmarried women are less likely than married women to refer to reproductive health services. For example, in India the percentage of unmarried women seeking treatment for genital infections was lower than that of married women (57\% versus 66\%) (9). Different reasons are cited why unmarried women use reproductive health services less than married ones, such as the intellectual and cultural backgrounds of societies, the ways services are offered and the performance of health staff (10). For example, in some countries reproductive health providers do not recognize the needs of young people nor do they welcome providing services to them, especially those who are unmarried (11). Staff seem uncomfortable talking to unmarried individuals, especially women, about sex and family planning. They rarely attempt to gain women's trust or keep their privacy. Therefore reproductive health services for unmarried women are usually provided by the private sector (12). Yet studies have also shown that young people, single individuals, minorities, the illiterate and the poor are more likely to depend on public reproductive health services because of financial problems and lack of insurance coverage (13).

Although reproductive health services are provided widely and are publicly available in the Islamic Republic of Iran, studies have shown unmet reproductive health needs of young people $(14,15)$. Like other services, reproductive health services are influenced by factors such as availability, price, quality, sociocultural factors and the characteristics of clients using them (16), and it may be that a lack of attention to these features makes these services unattractive for young and unmarried people (17). In a literature review, the researchers found a gap in existing knowledge about the state of reproductive health care services in the Islamic Republic of Iran from the perspective of unmarried women. This qualitative study in Isfahan city aimed to explore facilitators and barriers to the use of reproductive health services in public health care centres from the perspective of unmarried women.

\section{Methods}

A qualitative study was conducted within a naturalistic paradigm ${ }^{1}$ and a conventional content analysis of interview responses to explore the characteristics of publicly-funded reproductive health services from the perspective of participants.

\section{Study setting}

Government programmes in the Islamic Republic of Iran offer reproductive health services through a network organized on 3 levels: rural and urban health centres; public hospitals; and hospitals with specialty and subspecialty sections. The lowest level in cities is the urban health care centre (18). Isfahan city (the research location) with a population of 1.796 million (19) has 42 health care centres, and each health centre serves a population of 15000 people. In these centres, general practitioners, midwives and family health professionals are responsible for reproductive health services, including training, counselling, prevention and treatment in the areas of family planning, breast and cervical cancer screening, prenatal care, sexual health and infections (18). In this research, only features of the services provided by the publicly-funded system at health centres were studied.

\footnotetext{
Qualitative inquiries done within a naturalistic paradigm assume there are multiple, socially constructed realities; subjectivity is important; and the findings of the research are created with an interactive link between the researcher and participants. This contrasts with quantitative inquiries done within a positivist paradigm, which assumes there is one reality that is knowable within a specified level of probability; objectivity is important; and the findings of the research are achieved with manipulation and observation of variables in a dispassionate, objective manner.
} 


\section{Participants}

Purposive sampling was performed to select unmarried women from among those attending various educational, health and cultural centres in Isfahan city. The criteria for selection were unmarried women aged 25-60 years living in Isfahan city, who were not legally or traditionally married (based on self-reporting), had experience of visiting health centres (for various reasons) and gave informed consent to participate in the study. The researcher contacted the centres to obtain contact phone numbers for individual women or a family member of the women. In some cases, the staff of these centres provided the telephone numbers of potential clients who met the eligibility criteria. The researcher then telephoned the women, explained the aim of the study, checked the inclusion criteria and asked about their willingness to participate in the study. Participants were selected to have a maximum diversity in age, education and socioeconomic status. A number of service providers who had at least 6 months of experience in providing reproductive health services were also recruited into the study and interviewed.

\section{Data collection}

Each interview location was determined by the participant herself, e.g. in a medical centre, at the workplace or elsewhere. Data were collected through semi-structured in-depth interviews, and a few questions were used to guide the interview. Participants were asked what they knew of the reproductive health services offered at public centres, what situations and circumstances they had confronted, and how they would assess the current status of reproductive health services offered to unmarried women at government health centres. Based on participants' responsiveness, interviews lasted 15-65 minutes and were continued until the data were saturated, meaning there was no additional information that merited extracting a new code.

All ethical considerations, such as introducing the researcher, explaining the objectives of the study to the participants, giving them the option to leave the study at any time, keeping their information confidential, etc., were followed. All participants gave oral and written consent before any interviews were conducted.

\section{Data analysis and validation}

The conventional content analysis method proposed by Graneheim and Lundman was used to analyse the data (20). Content analysis is usually used when knowledge about the phenomenon is limited. Therefore the researchers allowed the formation of codes and categories emerging from the actual research data instead of using predetermined codes from theory. In this study, each interview was transcribed and analysed as soon as possible, for example on the day of interview or next day after recording. After full transcription, the text was read line by line, semantic units were specified and the compact semantic units and codes were extracted. Then data reduction took place. Finally, subcategories and categories of analysis emerged from these codes (21).

To obtain a rich picture of the phenomena being studied the researchers conducted in-depth interviews at different times and places and participants were selected with wide criteria (i.e. from different levels of education, socioeconomic status and age) to ensure maximum variation. To ensure the accuracy of the study, the 4 criteria proposed by Polit et al. - credibility, dependability, transferability and confirmability - were used (22). The codes were reviewed and their accuracy was confirmed by participants to guarantee the credibility of the research. The dependability of the study was ensured by using an external supervisor. To ensure transferability the results were assessed and confirmed by other unmarried women who had similar characteristics to the participants but who did not participate in the study. The researchers ensured confirmability by using a coding process, and peer reviewers assessed its authenticity.

\section{Results}

A total of 17 unmarried women within the age range of 27 to 53 years were enrolled into the study. Their educational levels varied from primary school to Master's degree, and most of them were employed. Furthermore, 7 midwives and 2 gynaecologists, with a mean occupational experience of 23 and 7 years respectively, participated in the study.

Data analysis led to the emergence of a list of favourable and unfavourable characteristics of reproductive health services, with several subcategories in each. Favourable characteristics (facilitators) were seen to be services that were delivered by female personnel/ in a woman-friendly environment; did not make clients feel labelled; and were delivered at an appropriate cost. Unfavourable characteristics (barriers) were services in which clients' privacy was not respected; clients felt uncertain about the confidentiality of private information; single women were not addressed in reproductive health services and programmes; there was no information dissemination about the content of services and how to use them; and clients had doubts about the quality of services (Box 1).

\section{Favourable characteristics of reproductive health services}

Services delivered by female personnel in a woman-friendly environment

In the culture of the Islamic Republic of Iran, women tend to avoid discussing reproductive health-related issues in the presence of men, and this affects the delivery of health 


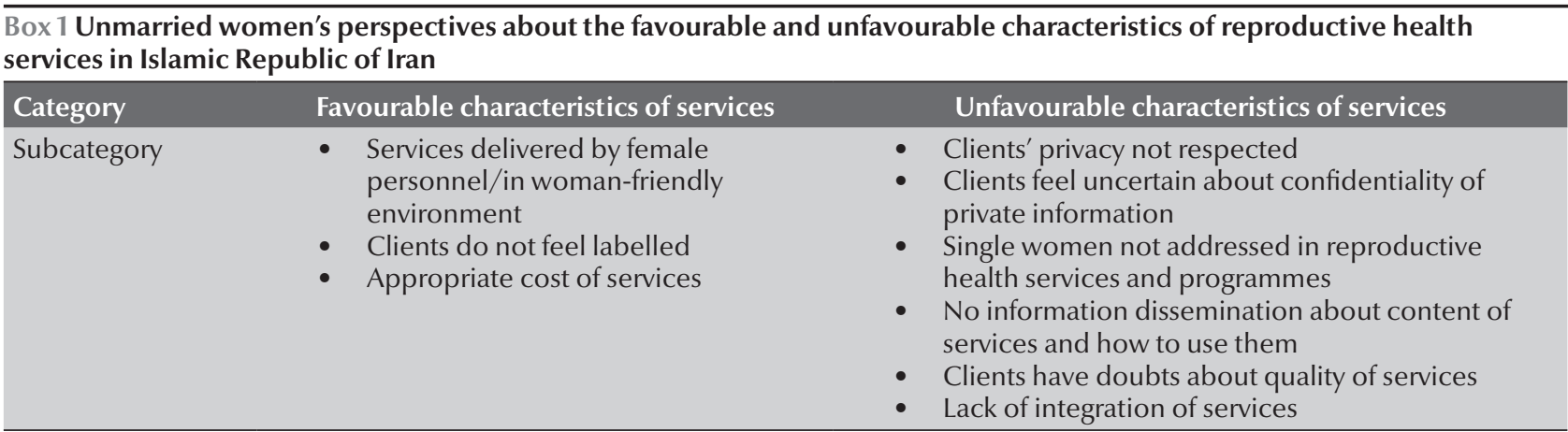

services. Unmarried women in our survey expressed a preference for an environment where they did not face male employees or clients when receiving reproductive health services. Participants stated that having female staff in public health centres encouraged them to seek services there. In this regard, one 31-year-old participant said, "Health centres are very good for providing services to unmarried women, as the staff and clients are women and women often go there".

One aspect of the desire to receive services from personnel of the same sex concerns Islamic religious beliefs concerning modesty of women's dress and interactions between men and women. A 31-year-old woman said, "I think one reason can be religious beliefs. Girls who insist more on hijab are more ashamed. These people avoid receiving services, especially from male physicians and staff'.

\section{Clients do not feel labelled}

Another particular expectation of unmarried women was to receive reproductive health services that would not lead to "labelling", i.e. feeling that they had done something deviant or outside the norms of society. Participants stated that unmarried women could refer to public health centres to receive reproductive health services without the fear of being "exposed", because of the different types of services being offered in these centres, such as prenatal care, child care and elderly care. A 29-year-old unmarried woman reported, "Using public services is very good for singles. Singles are more comfortable in this way, I suppose, because they come to a centre where everyone goes; their frequent referral would not be noticed, and they would not be separated from the rest by using special labels".

Participants declared that because clients attended public health centres for various reasons, single women did not need to fear that other people would suspect the reason for their visit and judge them in their minds. Thus, they could more easily use public reproductive health services. A 35-year-old woman said, "The environment of the health centres is suitable for providing services to single women as it is not a special centre where only a certain class would go to. It is a public place. When a place has a special name, others look at visitors there in a special way. In fact, when someone goes to the health centre, others do not particularly judge the person".

\section{Appropriate cost of services}

Participants stated that the economic dependency of some unmarried women on the family made public reproductive health service a good option for them, because these services cost less than services are offered by the private sector. One 28-year-old participant said, "I think the public centres are better for single people, because the price is so much better than private services; the costs are more appropriate and it is easier for us to pay".

\section{Unfavourable characteristics of reproductive health services}

\section{Clients' privacy not respected}

Respect for personal privacy was of particular importance for unmarried women seeking reproductive health services. In the context of this study, talking about issues related to sexual and reproductive health was accompanied by great shame, particularly for single people. The participants said that unmarried women expected their privacy to be respected completely while they receive services, so they could discuss their problems related to reproductive health without worry. In this respect public health centres were not seen as suitable since they are used for the clinical training of students. Participants mentioned the presence of students as a barrier to having personal privacy. A 53-year-old unmarried woman said, "If I need services, I'd rather go to a private clinic, because health centres are busy and are for training students. Therefore, I feel so embarrassed that I cannot express my problem in their presence".

It seems that the presence of students was not the only reason for lack of privacy in these centres. Another factor was that public health centres are crowded; several clients may enter the service provider's room simultaneously, and this reduces the possibility of privacy being respected. A 31-year-old unmarried participant reported, "Public centres are too crowded. Sometimes 3 or 4 patients enter the room at the same time. In some places, there are constant 
comings and goings to the room. I want myself and the health provider to be alone so that I can talk comfortably and no one else hears my words".

\section{Clients feel uncertain about confiden- tiality of private information}

Confidentiality of information when seeking reproductive health services was also of particular importance for unmarried women. They preferred to communicate quickly with service providers without having to discuss things with other staff (e.g. reception staff) or other providers of health centres who are not specialized in reproductive health. The public health care system is unable to meet this expectation of unmarried women, as the system is structured in such a way that clients need to visit different staff to get the required service. A 30-year-old unmarried woman said, "The place where services are offered must be determined at these centres, and each should have a special sign so that you deal less with other staff. The reason is the sense of shame or fear of others' looks. Other people usually thought badly of reproductive health problems in single women".

Among other expectations of unmarried women was the need to ensure confidentiality of their visit information. In public health care centres, the private information of clients must be registered in different steps within the service utilization process. Thus unmarried women were constantly concerned about the disclosure of this information and this was a barrier to referring to these centres. A 43-year-old unmarried woman said, "I am reluctant to go to health centres, because I do not want any of my information to be recorded. I always worry that a familiar person will be informed of my information".

\section{Single women not addressed in repro- ductive health services/programmes}

The target population of reproductive health services of Islamic Republic of Iran is married women. After their information is registered in the household file, women can refer to public health centres for different services. Participants of the current study stated that the data of single women were not registered in these centres. Thus, it seems that the staff of public health centres had no sense of responsibility towards them and in some cases refused to see them. This was a barrier to unmarried women attending public reproductive health services. One of the health care personnel said in this regard, "When an unmarried woman comes, and I ask her where her data is, she says that she has no registered file, since we do not register their data here. It is not among our rules to file their data".

This aspect of service provisionthe need to have a registered file-is effective for the implementation of many other health programmes by publichealthcentres. Yet, according to participants' statements, no guidelines about the screening projects related to reproductive health are available concerning single women or other people who have no information on file. This creates a barrier for unmarried women to receive reproductive health services in public centres. A midwife said, "It is interesting that the instructions for the breast disease screening stated that women aged between 18 to 65 years should be assessed. Even if they are unmarried, they should refer for yearly breast examination. Even so, nothing is actually done. There is no information given regarding unmarried women".

\section{No information dissemination about content of services and how to use them}

According to participants' reports, knowledge about the content of public reproductive health services and how to use them was important for unmarried women to make the decision to use the services. Our interviews showed that there was a lack of information about the services available and how to access them and this was a problem for unmarried women in the area of public reproductive health services. A 29-year-old participant said, "Giving information is more important than the services, as many do not know what services are provided in health care centres and whether the services can be used for singles or not. I, too, do not know where I can go. I just know that there are gynaecologists, and the health centre is only for married women".

\section{Clients have doubts about quality of services}

Participants also said that the quality of reproductive health services provided was a major factor in their use of services. Single women participating in this study needed to have confidence in the skills and scientific ability of the staff providing services in public health centres and also in the integration of offered services.

The participants stated that doubts about the skill and scientific ability of public health centre personnel meant they would avoid visiting these centres. A 34-year-old woman reported, "During my visits to health centres, I have seen the staff assess the patients very fast. One does not know whether the personnel are doing their job right or not, or if they have the necessary skills and expertise to do the job or not. That's why my first choice was always going to private centres". It seems that one cause of participants' doubts about the skills and scientific ability of public health centre staff was a lack of familiarity with the range of functions and capabilities of the staff. Another participant said in this regard, "I chose to go to a specialist's private office because I did not trust the expertise of personnel of health centres. Maybe I could go to these public centres, but I do not know if the staff of these centres can recognize my disease and treat me". 
Some unmarried women stated that during their visits to public health centres they faced unfriendly attitudes and ridicule from the staff and they felt that their problems were not taken seriously. This could indicate the personnel's lack of skill in communicating with single women. A 31-year-old unmarried woman described her experience visiting a public centre, saying, "My sister once told me that she felt something tight in her breast. We went to a nearby health centre, visited one of the staff, and explained the problem. She said, without examination, that such a problem is impossible in a single woman; she made fun of us, and said that you're a virgin and should not talk about these issues. As a result, we both got embarrassed and went back home".

\section{Lack of integration of services}

The women also expressed concern over the lack of integration of services in public health centres. Participants stated that unmarried women wanted to receive reproductive health services from a centre that provided different types of service in one place. A 35-year-old woman said, "I did not go to health centres, because I wanted to go somewhere that I can get my ultrasound, diagnostic tests and medication prescriptions for my disease". One of the reasons that unmarried women wanted more integration of services was their desire to reduce the number of referrals. It seems that this was because of their shame and fear of judgement from others concerning their use of reproductive health services. A 38-year-old woman said, "When an unmarried woman comes to get service from these centres, fixing their problem should not be postponed. This person must be able to receive the needed service quickly. In these centres, it should not be said to single people that there is now no possibility of serving you and please come another day".

\section{Discussion}

Our sample of Iranian unmarried women reported that the favourable characteristics of reproductive health services in public centres were services that were delivered by personnel of the same sex in a woman-friendly environment; that did not label clients; and that were available at a suitable price. In contrast, the following made public health centres undesirable for unmarried women: not addressing single women in the provision of reproductive health services; lack of privacy; failure to maintain confidentiality; poor skills and scientific ability of personnel; and lack of integration of services.

An effective reproductive health service needs to provide different services and should include people at all ages and both sexes. In some countries such as the Islamic Republic of Iran, reproductive health services are not be designed to cater for unmarried individuals. Talking about sexual and reproductive health in these cultures is taboo, and the use of such services by single people is accompanied by specific sensitivities and is associated with a sense of shame $(12,23,24)$. These issues mean that factors such as confidentiality and privacy are especially important for unmarried people when they use these services. Furthermore, feeling that they would not be labelled was an important factor facilitating unmarried women's utilization of reproductive health services. It seems that a strong emphasis on this characteristic of services is needed to avoid stigmatization of single individuals in diseases related to reproductive and sexual health. Shaikh and Hatcher suggested that private health services were used more than public services in developing countries because of the greater availability of private care for diseases and problems that could cause a patient to be stigmatized in the community (25).

A woman-friendly environment was also found to be a desirable feature of reproductive health services in public health centres. Studies in other countries have shown that women are generally less interested in visiting service providers of the opposite sex for issues related to sexual and reproductive health (13). In addition, male personnel and physicians do not feel comfortable when doing examinations or taking women's history, and they use a chaperone, a person who accompanies them during physical examinations, much more than women physicians $(26,27)$.

Another favourable property of public services from the point of view of our respondents was proper pricing. Participants mentioned the financial dependency of unmarried women on their families or having a low income as the reasons for this. There is evidence that lower-income populations who are confronted with financial restrictions depend more on public services and services provided by general practitioners because of the lower pricing $(28,29)$.

Our results showed that doubts about quality was one of the undesirable characteristics of public services and was a reason for not using such services according to our respondents. Other studies have also demonstrated that patients' perception of the quality of services plays an important role in the use of such services. In some cases, it was an even more important factor than geographical access $(13,30)$.

Not considering single women as a target population in the design of public reproductive health services was another weak point. A perceived discrimination in the provision of services reduced the ability of such women to access services. In a similar study in the Islamic Republic of Iran, the majority of young people reported an inadequate availability of services (78\%) and barriers to accessing these services as reasons for the lack of use of reproductive health services (14). It seems that this is a central finding of the study. It shows that despite the demographic changes in 
the Islamic Republic of Iran in recent years - which have led to an increase in the youth population and in the proportion of unmarried people - the health system has changed little in its methods of service delivery. In other words, the health system has not been responsive to the reproductive health needs of the younger generation or to the related sociocultural changes. It can be concluded that improvements in the infrastructure of the service provider system are necessary to meet the needs of unmarried women and to facilitate their use of services. This includes preserving confidentiality during visits, providing more privacy for clients and ensuring better integration of the available reproductive health services. Furthermore, women's doubts about the quality of services, and their lack of satisfaction with the personnel's communication skills, point to a need to upgrade human resource skills via review of training methods and an evaluation of health centre personnel's performance.

There were some limitations to the study. Although the small sample size of qualitative studies is a limitation which decreases the generalizability of the results, efforts were made in this study to overcome this limitation by the inclusion of individuals with different attributes in the study sample. Furthermore, the study was carried out in Isfahan city, which is one of the central metropoles of Islamic Republic of Iran and, because of its job opportunities, has a large population from other parts of the country. Thus Isfahan can be seen as to some extent representative of the country's culture. The Islamic Republic of Iran has an Asian culture with a dominant Muslim population and therefore the results may be applicable in other societies throughout the region that have a similar culture and religion.

\section{Conclusions}

In general, it seems that the reproductive health service provided at Iranian public health centres needs more flexibility to adapt to the sociocultural changes that have occurred in the country. Policymakers in the health sector should constantly monitor the changing health needs of each generation and consider the necessary measures to ensure they meet the health care needs of the public.

\section{Acknowledgements}

The authors acknowledge all the participants in this study. Without their cooperation and sympathy this study would not have been possible.

Funding: This study was partly funded by the Medical Sciences University of Isfahan (No. 392478).

Competing interests: None declared.

\section{References}

1. Enayat H, Movahed M. Women and structural transformation of society in the age of globalization. Women Res. 2004;2(2):153-66. [Persian]

2. Ahmadi V, Ghasemi V, Kazemipoor S. [The role of demographic transition in the sociological changes in family]. PsychosocSoc Women Stud. 2012;10(1):81-101. [in Farsi]

3. Ahmadi V, Hemati R. [Evaluating the limitations of marriage, according to census of 2006]. Women Strategic Stud. 2008;11(41):43-64. [in Farsi]

4. Kazemipoor S. [Change in age at marriage and its effective population factors]. Women Res. 2004;2(3):103-24. [in Farsi]

5. Population 10 years and over by age, sex and marital status [Internet]. Tehran: Iran Statistics Centre; 2012 (http://salnameh. sci.org.ir/TableShow/printversion.aspx, accessed 20 December 2015).

6. Barooti E, Taeri S, Siroos S. Macro strategies of women's health in Islamic Republic of Iran [Internet]. Tehran: Health Ministry of Iran; 2006 (http://siasat.behdasht.gov.ir/index.aspx?siteid= 291\&siteid=291\&pageid=36776, accessed 20 December 2015).

7. Loaiza E, Blake S. How universal is access to reproductive health? A review of the evidence. New York (NY): United National Population Fund; 2010 (http://www.unfpa.org/sites/ default/files/pub-pdf/universal_rh.pdf, accessed 20 December 2015).

8. Women and health: today's evidence tomorrow's agenda Geneva: World Health Organization; 2009.

9. Sabarwal S, Santhya KG. Treatment-seeking for symptoms of reproductive tract infections among young women in India. Int Perspect Sex Reprod Health. 2012 Jun;38(2):90-8. PMID:22832149
10. BottS, Jejeebhoy S, Shah I, Puri C. Towards adulthood: exploring the sexual and reproductive health of adolescents in South Asia. Geneva: World Health Organization; 2003 (https://extranet. who.int/iris/restricted/bitstream/10665/42781/1/9241562501. pdf, accessed 20 December 2015).

11. DeJong J, El-Khoury G. Reproductive health of Arab young people. BMJ. 2006 Oct 21;333(7573):849-51. PMID:17053245

12. Sychareun V. Meeting the contraceptive needs of unmarried young people: attitudes of formal and informal sector providers in Vientiane Municipality, Lao PDR. Reprod Health Matters. 2004 May;12(23):155-65. PMID:15242224

13. Habtom GK, Ruys P. The choice of a health care provider in Eritrea. Health Policy. 2007 Jan;80(1):202-17. PMID:16647156

14. Simbar M, Tehrani FR, Hashemi Z. Reproductive health knowledge, attitudes and practices of Iranian college students. East Mediterr Health J. 2005 Sep-Nov;11(5-6):888-97. PMID:16761658

15. Dolatian M, Hajian S, Simbar M, Alavi-Majd H. [Knowledge and attitude of nonmedical students regarding reproductive health]. J Nurse Midwifery. 2007;17(56):3-16. [in Farsi]

16. Chakraborty N, Islam MA, Chowdhury RI, Bari W, Akhter $\mathrm{HH}$. Determinants of the use of maternal health services in rural Bangladesh. Health Promot Int. 2003 Dec;18(4):327-37. PMID:14695364

17. Health and human rights. Fact sheet No. 323 [Internet]. Geneva: World Health Organization; 2015 http://www.who.int/mediacentre/factsheets/fs323/en/, accessed 20 December 2015)

18. Asadi-Lari M, Sayyari AA, Akbari ME, Gray D. Public health improvement in Iran-lessons from the last 20 years. Public Health. 2004 Sep;118(6):395-402. PMID:15313592 
19. Publications information base [Internet]. Isfahan: Governor of Isfahan, Vice-Chancellor of Planning, Office of Statistics and Information; 2002 (http://amar.ostan-es.ir, accessed 20 December 2015).

20. Hsieh H-F, Shannon SE. Three approaches to qualitative content analysis. Qual Health Res. 2005 Nov;15(9):1277-88. PMID:16204405

21. Graneheim UH, Lundman B. Qualitative content analysis in nursing research: concepts, procedures and measures to achieve trustworthiness. Nurse Educ Today. 2004 Feb;24(2):105-12. PMID:14769454

22. Polit DF, Beck CT. Nursing research: generating and assessing evidence for nursing practice. Philadelphia (PA): Lippincott Williams and Wilkins; 2008.

23. Abedian K, Shahhosseini Z. University students' point of views to facilitators and barriers to sexual and reproductive health services. nt J Adolesc Med Health. 2014;26(3):387-92. PMID:24243747

24. Lindberg C, Lewis-Spruill C, Crownover R. Barriers to sexual and reproductive health care: urban male adolescents speak out. Issues Compr Pediatr Nurs. 2006 Apr-Jun;29(2):73-88. PMID:16772237
25. Shaikh BT, Hatcher J. Health seeking behaviour and health service utilization in Pakistan: challenging the policy makers. J Public Health (Oxf). 2005 Mar;27(1):49-54. PMID:15590705

26. Politi MC, Clark MA, Armstrong G, McGarry KA, Sciamanna $\mathrm{CN}$. Patient-provider communication about sexual health among unmarried middle-aged and older women.J Gen Intern Med. 2009 Apr;24(4):511-6. PMID:19219512

27. Price DH, Tracy CS, Upshur RE. Chaperone use during intimate examinations in primary care: postal survey of family physicians. BMC Fam Pract. 2005;6(1):52. PMID:16371153

28. Khe ND, Toan NV, Xuan LT, Eriksson B, Höjer B, Diwan VK. Primary health concept revisited: where do people seek health care in a rural area of Vietnam? Health Policy. 2002 Jul;61(1):95109. PMID:12173499

29. Frost JJ. Public or private providers? U.S. women's use of reproductive health services. Fam Plann Perspect. 2001 JanFeb;33(1):4-12. PMID:11271546

30. Duong DV, Binns CW, Lee AH. Utilization of delivery services at the primary health care level in rural Vietnam. Soc Sci Med. 2004 Dec;59(12):2585-95. PMID:15474211 